\title{
THE EFFECT OF MANUALLY CONTROLLED DYNAMIZATION ON THE LENGTHENED CALLUS - PRELIMINARY RESULTS
}

\author{
Sándor Berki ${ }^{1}$, György Szőke ${ }^{2}$, Károly Pap ${ }^{3}$ \\ ${ }^{1}$ Department of Traumatology and Bone\&Joint Reconstructive Surgery, Szentes University \\ Teaching Hospital \\ ${ }^{2}$ Department of Orthopaedics, Semmelweis University of Budapest \\ ${ }^{3}$ Department of Traumatology and Uzsoki Hospital Budapest, Semmelweis University \\ of Budapest \\ drpapster@gmail.com
}

\begin{abstract}
The present study evaluated the radiological changes in normal and dynamized callus after limb lengthening in New Zealand White rabbits. The aims of the study were to create a lengthening device that allows axial controlled manual dynamization and to examine the effect of the maximal amount of dynamization on the healing, lengthened callus.

10 male domestic white rabbits were divided into two groups (normal distraction group (NDG) and dynamized distraction group (DDG)). Osteotomy was followed by distraction at the same rate and total length in both groups, but in the dynamized distraction group $1 \mathrm{~mm}$ manual dynamization was performed for ten minutes three times a day prior to lengthening. Callus formation and lengthening were analysed on the X-ray pictures and on the three-dimensional CT image respectively. Neither malposition of the pins nor maluninon were found during or after the distraction period. No significant difference was found in the amount of the callus between the NDG and DDG.

A lengthening device was created that allows axial controlled manual dynamization and prevents instability in the other two axes and our results showed that this large amount of dynamization did not decrease the formation and quality of the callus.
\end{abstract}

Keywords: manual controlled dynamization, callus distraction, limb lengthening, Micro Computed Tomography

\section{Introduction}

Graded limb lengthening by callus distraction (callotasis) is a widely used surgical procedure to correct tubular bone deformities on both lower and upper extremities ${ }^{8}$. Although the functional improvement in children and changes in their quality of life are dramatic after surgery ${ }^{14}$, it takes a long time for the patient and the orthopaedic surgeon to achieve the desired result. The usual healing index of long tubular bones is $25-40 \mathrm{day} / \mathrm{cm}$.
For the correction of an average $5 \mathrm{~cm}$ difference between the extremities patients have to wait 125-200 days for the fixator to be removed.

It has been suggested that dynamic loading enhances fracture healing by stimulating the osteogenic response during the healing process, but the exact biologic mechanism for such an effect is unknown ${ }^{2,4}$. At least three different types of dynamization can be identified based on the properties of the fixator system 
used. Elastic dynamization occurs when the fixator frame and pins deform under physiologic loading ${ }^{1}$. The second type is when the external fixator frame allows free axial movement through a telescopic mechanism incorporated in the body of the fixator, while bending and rotation is prevented ${ }^{4}$. The third type is through a powered actuator attached to the pins or the fixator frame capable of loading bone ends dynamically irrespective of physiologic and functional loading. This is called controlled dynamization?.

It is recognized that the optimal range of interfragmentary movement (IFM) stimulates bone healing and callus formation ${ }^{6,13}$. However little is known of the optimal IFM or effect of dynamization on the healing process $^{3}$.

The authors wanted to combine the benefits of manually controlled dynamization with callus distraction. The aims of the study were to create a lengthening device that allows axial controlled manual dynamization and prevents instability in the other two axes. The effect of the maximal amount of dynamization (same rate as the daily lengthening) on the healing, lengthened callus was also examined.

\section{Materials and methods}

The experimental procedures were carried out on New Zealand White rabbits of both sexes weighing $2.5-3.0 \mathrm{~kg}$. All animal experiments were performed in accordance with the European Communities Council Directive of 24 November 1986 (86/609/ECC) and were approved by the Committee on Animal Experiments, Semmelweis University, Budapest, Hungary. All efforts were made to minimize the number of animals used and their suffering.
Insertion of an external skeletal fixator and osteotomy was performed ${ }^{11}$ under deep ketamine-medetomidine general anesthesia ( $25 \mathrm{mg} / \mathrm{kg}$ and $0.5 \mathrm{mg} / \mathrm{kg}$ i.m., respectively) in 10 rabbits. The skin was incised on the medial aspect of the hind limb and the tibia was exposed. Modified and original Orthofix-M 101 minifixator with four self-drilling cortical screws was applied and transverse tibial osteotomy was performed.

The modified fixators contained a dynamization screw, which allows $1 \mathrm{~mm}$ interfragmental active dynamization in a $360^{\circ}$ turn (Figure 1). Caution was exercised to avoid damaging nerves, muscles and other soft tissues. 7 days latency after the operation the lengthening were performed. The 10 rabbits undergoing the surgical procedure were divided into two groups ( $\mathrm{n}=5$ for each group): in the normal distraction group (NDG) osteotomy was followed by distraction initiated at a rate of $1 \mathrm{~mm} /$ day done once a day until the bone had reached $120 \%$ of its original length. In the dynamized distraction group (DDG) osteotomy was followed by distraction at the same rate and total length as in the NDG. Prior to

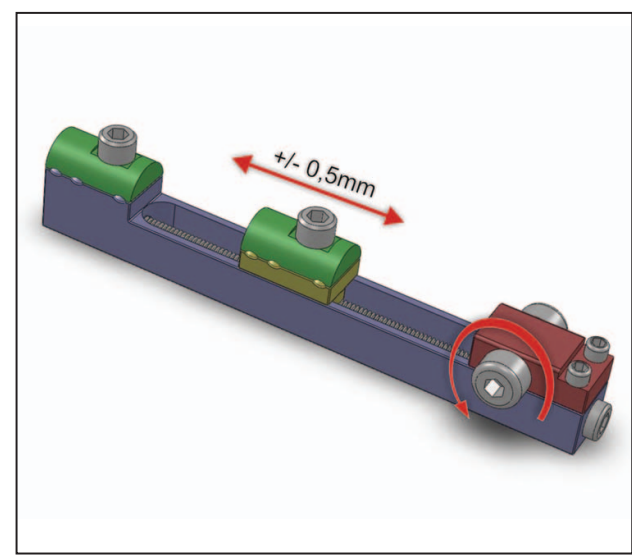

Figure 1. The modified fixators contained a dynamization screw (shown with the curved red arrow), which allows $1 \mathrm{~mm}$ interfragmental active dynamization in a $360^{\circ}$ turn 
lengthening was done $1 \mathrm{~mm}$ manual dynamization was performed for ten minutes three times a day. Lengthening was performed, at the end of the day. Great care was taken to fix the dynamization screw in the daily starting position. In this way it was possible to ensure that the daily lengthening would be exactly $1 \mathrm{~mm}$. At the end of the distraction the animals

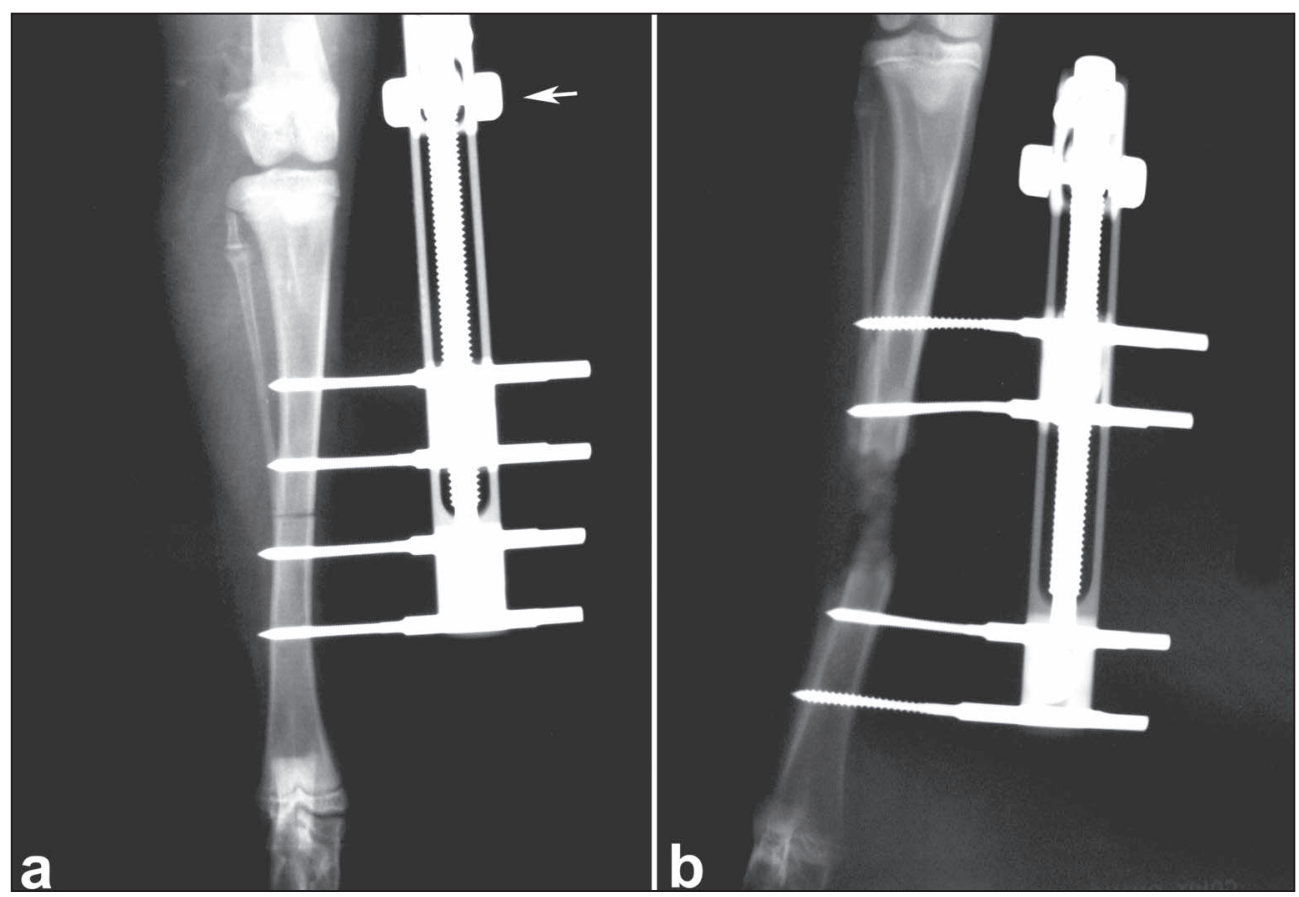

Figure 2. Postoperative radiographs of a rabbit from the DDG. a) right after the operation; $b$ ) at the end of the lengthening. The white arrow points to the dynamization screw

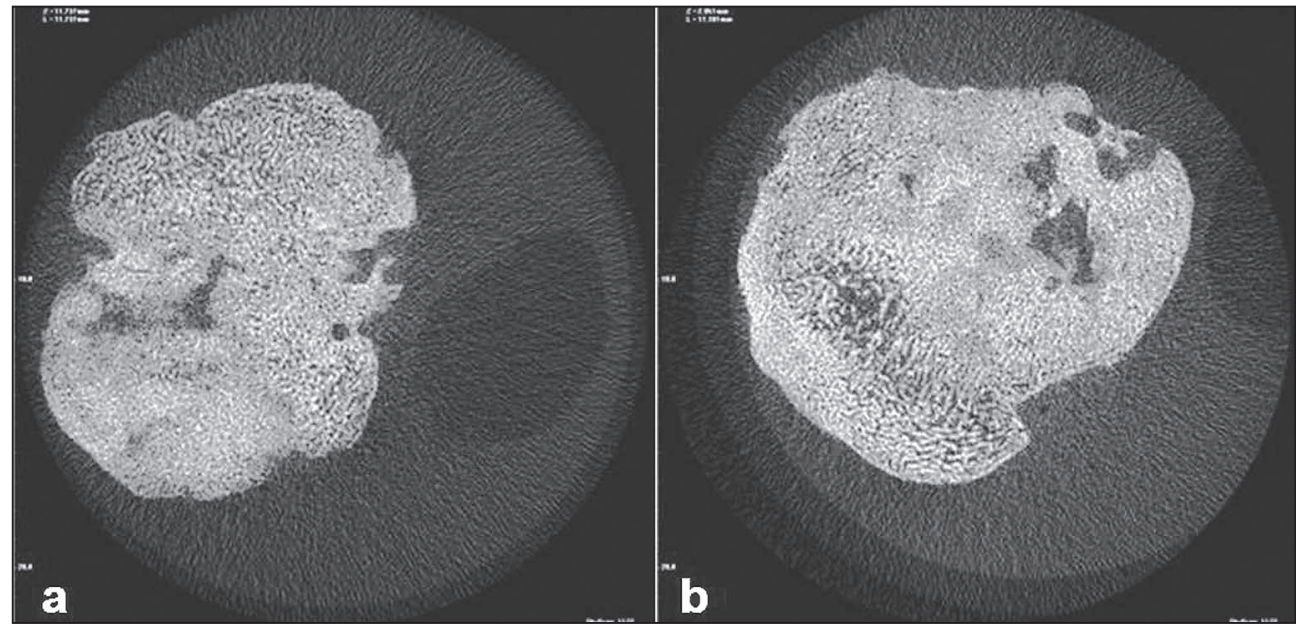

Figure 3. Cross sections of the callus from NDG $a$ ) and from the DDG $b$ ) 
were sacrificed. Two postoperative radiographs (the first taken immediately after the operation, the second at the end of the lengthening period both in standard dorsoplantar and mediolateral projections $50 \mathrm{kV}, 8.0 \mathrm{mAs}$ ) and mCT scan were made (Figure 2, 3).

\section{Micro Computed Tomography}

Bones were imaged (Figure 3) at an isotropic voxelsize of $17 \mu \mathrm{m}$, using a mCT Cone Beam 1172 SkyScan system (SkyScan, Kontich, Belgium) operating at a peak voltage of $100 \mathrm{kV}$ and $100 \mu \mathrm{A}$ with a $0.5 \mathrm{~mm}$ aluminum filter. Samples were rotated until 180 degrees with a rotation step of 0.70 degrees and a frame averaging of 3. Three-dimensional reconstructions of the images were visualized using NRecon software (SkyScan, Kontich, Belgium) with $50 \%$ beam hardening and $20 \%$ ring artifact correction (Figure 4). Global thresholding was performed by the experienced operator. The image datasets were analysed by CT Analyser software (1.7.0.5, SkyScan, Kontich, Belgium) to evaluate bone volume (BV), bone surface (BS), total volume (TV), bone volume fracture (BV/TV).

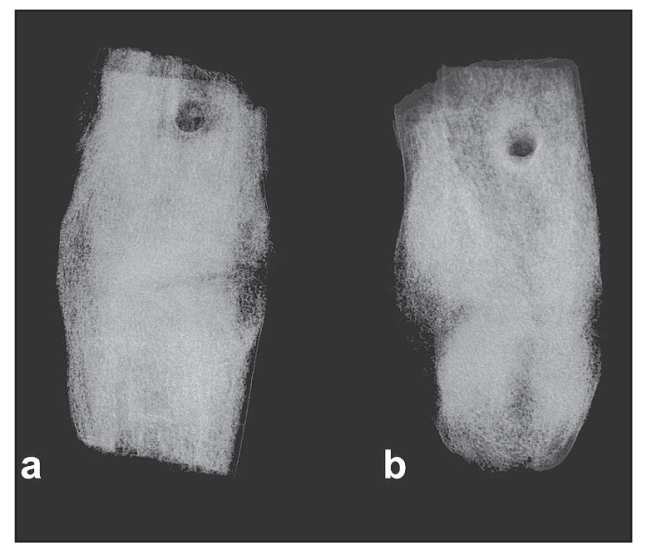

Figure 4. 3D reconstruction of the lengthened callus in a rabbit from the NDG $(a)$ and from the DDG (b)

\section{Statistical Analysis}

First a normality test was done. The BV, BS and BV/TV data underwent testing and then a t-test was performed. Normality assumption was not met at TV data, then a Mann-Whitney Rank Sum Test was performed Analyses were performed using a software SigmaStat 2.0, with a level of significance set at $p<0.05$.

\section{Results}

Following surgery, the rabbits were kept in separate standard cages $\left(0.5 \mathrm{~m}^{2} /\right.$ animal $)$ with food and water available ad libitum. The environment was maintained at $22 \pm 2{ }^{\circ} \mathrm{C}(60 \%$ humidity) with a $12 \mathrm{~h}$ light-dark cycle. All rabbits recovered well after surgery. During the study there was no observable prostration; lack of appetite and body weight loss of the animals. Furthermore, no signs of infection or inflammation were observed in any of the animals.

Two postoperative radiographs were taken. The positions of the pins were checked on the first radiogram. Callus formation and lengthening were analysed on the second X-ray picture and on the three-dimensional CT image respectively. Neither malposition of the pins nor maluninon were found during or after the distraction period. No visible difference in the amount of callus between the NDG and DDG was found.

The rabbits of the dynamized distraction group (DDG) presented $20 \%$ greater callus $\mathrm{BV}$, but no statistical difference was found $(p=0.27)$. If the BV/TV of the distracted area was evaluated $24 \%$ greater callus was found. There was no statistical difference between the groups $(p=0.233)$. Almost the same amount of callus TV was measured between the compared groups (Table 1). The new bone surface 


\begin{tabular}{|l|c|c|}
\hline & Normal distraction group & Dynamized distraction group \\
\hline Bone Volume $\left(\mathrm{cm}^{3}\right)$ & $0.3336 \pm 0.1228$ & $0.4157 \pm 0.0945$ \\
\hline Total Volume $\left(\mathrm{cm}^{3}\right)$ & $1.6033 \pm 0.1863$ & $1.5948 \pm 0.3147$ \\
\hline Bone Volume Fraction $(\mathrm{BV} / \mathrm{TV})$ & $0.2098 \pm 0.0799$ & $0.2646 \pm 0.0512$ \\
\hline Bone Surface $\left(\mathrm{cm}^{2}\right)$ & $2.5130 \pm 0.9350$ & $3.4835 \pm 0.9317$ \\
\hline
\end{tabular}

Table 1. Summarized data of $\mathrm{mCT}$ scan results

was slightly greater in DDG than in the NDG, but the difference was not significant $(\mathrm{p}=0.139)$.

\section{Discussion}

The effects of mechanical stimulation of fracture healing have been documented clinically, and it has been shown that appropriate axial stimulation facilitates bone fracture healing $^{7,10}$. The fact that some investigators formed the basis of the present study ${ }^{5,9}$. Later it was thought that mechanical stimulation of fractures should start after the appearance of callus ${ }^{12}$. When the callus reached $2 \mathrm{~mm}$ then the dynamization started.

We believe we achieved the aims of the study and created a lengthening device that allows axial controlled manual dynamization and prevents instability in the other two axis. No difference in stability, animal behaviour or complications between the two groups were found.

Dynamization is widely used for treating fractures. There is still no consensus in clear amount and daily frequency. In the present the effect of the maximal amount of dynamization (same rate as the daily lengthening) on the healing of the lengthened callus was tested. As this is a new fixator there are no standards for the frequency and amount of the dynamization during lengthening. In the first step maximum amount of dynamization beside the lengthening was attempted. No difference was found in the radiological properties of callus between the groups. Results showed that this large amount of dynamzation did not decrease the formation and quality of the callus. It can be said tentatively that dynamization slightly improved callus formation, but no statistical background was found. Our aim in the future to find the ideal amount and daily frequency of the dynamization during limb lengthening for increasing the callus formation. We are planning to change the daily active manual dynamization to computer assisted dynamization. With the help of these hopefully we will be able to easily control the steps of lengthening and dynamization and reach our final aim: faster new bone formation.

\section{REFERENCES}

1. Burny FL. Elastic External Fixation in tibial fractures: Study of 1421 cases. In booker AF.

2. Chao EYS, Aro H. Biomechanics of fracture fixation. In: Mow, Hayes WC, editors. Basic Orthopaedic Biomechanics. New York: Raven Press; 1991;293-335.
3. Claes L, Blakytny R, Göckelmann M, Schoen M, Ignatius A, Willie B. Early dynamization by reduced fixation stiffness does not improve fracture healing in rat femoral osteotomy model. J Orthop Res 2009;27:22-7. 
4. De Bastiani G, Aldegheri R, Brivio LR. Treatment of fractures with dynamic axial fixator. J Bone Joint Surg 1984;66B:538-45.

5. Egger EL, Gottsauner-Wolf F, Palmer J. Effect of axial dynamization on bone healing. J Trauma 1993;34:185-19.

6. Epari D, Kassi J, Schell H, Duda G. Timely fracture-healing requires optimization of axial fixation stability. J Bone Joint Surg Am 2007;89A: 1575-85.

7. Goodship AE. Cyclical micromovement and fracture healing. J Bone Joint Surg 1996;78: $166-7$.

8. Kiss S, Pap K, Vizkelety T, Terebessy T, Balla $M$, Szóke Gy. The humerus is the best place for lengthening. Int Orthop 2008 Jun;32(3):385-8.

9. Larsson S, Wookcheol K, Caja VL, Egger E, Inoue N, Chao EYS. Effect of early axial dynamization on tibial bone healing: a study in dogs. Clin Orthop Relat R 2001;388:240-51.
10. Martinez A, Sarmiento A, Latta LL. Closed fractures of the proximal tibia treated with functional brace. Clin Orthop 2003;417:293-302.

11. Pap K, Kiss S, Shisha T, Domos Gy, Berki S, Holnapy $G$ et al. Hisztopatológiai elváltozások az izomszövetben végtaghosszabbítást követően. Magyar Traumatológia, Ortopédia, Kézsebészet, Plasztikai Sebészet 2009;(3):217-22.

12. Takeda T, Narita T, Ito H. Experimental study on the effect of mechanical stimulation on the early stage of fracture healing. J Nippon Med Sch 2004;71:252-62.

13. Wolf S, Janousek A, Pfeil J, Veith W, Haas F, Duda $G$ et al. The effects of external mechanical stimulation ont he healing of diaphyseal osteotomies fixed by flexible external fixation. Clin Biomech 1998;13:359-64.

14. Young N, Bell D-F, Anthony A. Pediatric pain patterns during Lizarov treatment of limb length discrepancy an angular deformity. J Pediatr Orthop 1994;14(3):352-7.

\section{Dr. Károly Pap}

Department of Traumatology and Uzsoki Hospital Budapest, Semmelweis University of Budapest

H-1145 Budapest, Uzsoki u. 29.

Tel.: (+36) 1 467-3700 